Please refer to the definitive version of this article when citing:

Hanna, P., Kantenbacher, J., Cohen, S.A. \& Gössling, S. (2017). Role model advocacy for sustainable transport. Transportation Research Part D: Transport and Environment (In press).

\title{
Role model advocacy for sustainable transport
}

\begin{abstract}
Individual aspirations of associating with role models are routinely harnessed by marketers, who for instance, use celebrity endorsement in selling brands and products. It appears there has been no research to date, however, on the potential for celebrity activism, or role model advocacy beyond celebrities, such as from politicians, to form effective interventions for encouraging sustainable transport behaviour. This is despite studies suggesting that celebrity endorsement is a potential gateway for transforming public opinion on carbon intensive transport modes. The present paper consequently offers a critical review of the literature on role model advocacy and celebrity activism, and how these concepts have been harnessed to address environmental issues, in order to conceptually assess the potential for extending these intervention techniques to the context of sustainable transport. The scope of the paper includes the potential that high profile politicians/celebrities might play as role models in exercising referent power to influence social norms surrounding sustainable transport, given that the success of social marketing interventions are closely tied to the need for changes in the policy landscape. Key dimensions of role model endorsement in transport are identified and applied to a series of examples of how celebrity and political role models have influenced transport cultures. In addition to offering an original application of a theoretical framework to a new context, in order to help address the increasingly important societal issue of transport's growing contribution to climate change, the paper discusses the challenges associated with the neoliberal framing of this approach.
\end{abstract}

Keywords: celebrity endorsement, social marketing, sustainable transport, behavior change, identity, neoliberalism

\section{Introduction}

Wishing to identify or fit in with desirable individuals or reference groups is a primary motive for many consumption activities, especially those that are consumed publicly and may be considered a luxury. Aspirational reference groups, often consisting of idealized figures such as celebrities, athletes, successful politicians or business people, are particularly important in shaping the attitudes and behavior of others who desire to associate with them (Solomon, Bamossy, Askegaard, \& Hogg, 2006). Individual aspirations of associating with such role models are routinely harnessed by marketers, who for instance, use celebrity endorsement in selling brands and products. Referent power, that is, the power of reference groups to influence 
purchase decisions, is used to encourage consumers to copy the behavior of a person they may admire (Solomon et al., 2006).

Role model and celebrity endorsement have also been leveraged within the field of social marketing, which applies commercial marketing techniques to the solution of social problems, and focuses on consumers as active participants in processes of social change (Ampt \& Gleave, 2004; Andreasen, 1994; Hall, 2014). The aim of social marketing is consequently voluntary behavior change, targeted to a specific audience via market segmentation (Barr, Gilg, \& Shaw, 2011b). Although social marketing interventions, such as those within the health field that have, for instance, encouraged the public to exercise more, are criticized for only engendering small-scale behavioural change, which is often not sustained (Higham, Cohen, Cavaliere, Reis, \& Finkler, 2016; Peattie \& Peattie, 2009), considerable effort has been invested in social marketing interventions that use aspirational role models, such as celebrities, to influence public opinion on social issues. One such arena has been environmental issues (Goodman \& Littler, 2013), where celebrity activism has focused on advancing an environmentalist agenda (McCurdy, 2013).

It appears that there has been no research to date, however, on the potential for celebrity activism, or role model advocacy beyond celebrities, such as through politicians, to form effective interventions for encouraging sustainable transport behavior, particularly in terms of the conspicuous consumption of leisure travel. This is despite Higham et al.'s (2013) observation that celebrity endorsement is a potential gateway for transforming public opinion on carbon intensive transport modes, and Cohen et al.'s (2016) further emphasis that trends are fashion driven, with role model advocacy potentially playing a role in driving social norms that may help to constitute a desirable transport future.

The present paper consequently offers a critical review of the literature on role model advocacy and celebrity activism, and how these concepts have been harnessed to address environmental issues, in order to conceptually assess the potential for extending these intervention techniques to the context of sustainable transport. The scope of the paper includes the potential part that high profile politicians/celebrities might play as positive role models in exercising referent power to influence social norms surrounding sustainable transport, given that the success of social marketing interventions are closely tied to the need for changes in the policy landscape (Wymer, 2010). A range of examples of how celebrity and political role models have influenced transport cultures - for better or for worse - are discussed. In addition to offering an original application of a theoretical framework to a new context, in order to help address the increasingly important societal issue of transport's growing contribution to climate change, the article discusses the challenges associated with the neoliberalist framing of this approach.

In order to achieve this critical review, the paper opens with an overview of the need for sustainable transport behavior in contemporary societies. It then turns to literature that explores understandings of self and identity through modes of consumption. This provides a foundation that allows the paper to next move on to the ways in which celebrities feature within the self/identity/consumption nexus, particularly in relation to their social status and their ability in theory to endorse/not endorse the consumption of discrete products. Here a critical reading of the 'celebrity' is offered before the paper moves on to explore the potential role of celebrity endorsement and role model advocacy in sustainable transport consumption patterns/behavior. This theoretical framing is finally applied to sustainable transport behaviour, which allows for 
identification of key dimensions of role model endorsement in transport, and their application in a series of short illustrative examples. The paper concludes with a discussion of the implications of the review and the potential future research directions it opens up.

\section{The need for sustainable transport behavior}

Transport behavior is an arena of consumption associated with a wide range of environmental issues, such as noise, air pollution, accidents, and emissions of greenhouse gases (Gilbert \& Perl, 2008; Hook \& Replogle, 1996; Kenworthy \& Laube, 1999; Okokon et al., 2015; Stanley, Hensher, \& Loader, 2011). A wide range of organizations and politicians have acknowledged that the current transport system is not sustainable, with evidence that it is even becoming less sustainable over time with regard to key aspects such as transportation's contribution to global warming (Banister, 2005). Research has repeatedly underlined that technological innovation is unlikely to resolve these issues. Specifically, climate mitigation is unfeasible on the basis of technological change alone, as constant growth in transport demand outweighs efficiency gains by a wide margin (EEA, 2015; Peeters, Higham, Kutzner, Cohen, \& Gössling, 2016). This would call for policies aligning societal goals of sustainable transportation more closely with the development of the sector, but policy makers have been found to be reluctant to initiate sustainable transportation initiatives, which are seen to interfere with existing 'order', and likely to draw massive criticism from lobby organisations (Gössling \& Cohen, 2014). With regard to individual changes in behavior, there is no evidence of change that would lead to more sustainable transport systems, perhaps with the notable exception of cycling, where some progress has been observed in cities throughout the world in recent years (Pucher \& Buehler, 2012). In light of this, a key question thus remains how behavior can be influenced at large scales, and over comparably short periods of time, and whether significant others such as celebrities can inspire more sustainable transport behavior on larger societal scales.

\section{Consumption, self and identity}

Transport often involves consumption, whether that be purchasing a high-powered sports car, a trans-continental flight in business class or a bike to cycle to work. Such consumption decisions are inextricably bound up with one's sense of self and identity, and this is no secret to marketers, who leverage consumer identity concerns to sell products (Belk, 1988; Solomon et al., 2006).

Identity has generated considerable interest in the social sciences with numerous theoretical perspectives attempting to understand how identities are constructed and what this means for the individual. In what is often referred to as 'pre-modernity', it has been argued that fixed social structures, such as the church, family and work, contributed to the construction of individuals' identities and these remained relatively fixed throughout their lives (Baumeister, 1987). This ordering of individuals in relatively stationary social structures carried through into the industrial period /'modernity', however work and production played an increasing role in the process (Featherstone, 1991). Identity constructed through such structural channels offered individuals little agency and can been seen as 'ascribed' rather than 'achieved' (Dittmar, 2008). In contemporary societies it now appears that some of these previous social structures are fragmenting and there is more fluidity, with recent attention turning to how consumption is 
playing an ever-increasing role in the process of identity construction (e.g. Dittmar, 2008; Leighton, 2003; Mackay, 1997; Mackintosh \& Mooney, 2000; Miller, 1997).

Consumer goods are seen to play a strong psychological role for individuals in terms of emotional attachment, identity construction and social status. It is via consumption practices that individuals attempt to achieve an expression of the 'self' that is as closely related to the internalized idealized vision of the self we are said to possess (Dittmar, 2008). Consequently consumerism and the practice of consuming goods facilitates the expression of both public and private aspects of the self and makes it possible to achieve a particular identity (Richens, 1991). As Therkelsen and Gram (2008, p. 273) comment: 'consumption is thus a means of living out (perceived) choice and of expressing one's (perceived) unique inner core' (p. 273).

Kornberger and Brown (2007) suggest however that identity should not be understood as an 'essence'. Rather it is the result of complex power relationships within which an individual's identity is actively constructed yet also passively ascribed. Alternatively, Bauman (2001) proposes that the notion of expressing the self through consumption is a driver for the maintenance of consumer demand in modern capitalism via 'consumer desire'. Indeed, Cushman (1995) explores the ways in which 'empty selves' are constructed in contemporary society to position individuals in a circular relationship whereby consumption offers a key resource to fill the 'empty self', however this illusion can never be fulfilled, thus we consume to fill, but are once again returned to a state of emptiness. Further, class-based analysis claims that processes of distinction and 'othering' work through consumption practices (Lawler, 2005; Nayak, 2006; Skeggs, 2003). For example, Bourdieu (1984) suggests each class within society has access to particular consumer practices and symbols (e.g. clothing, food, leisure activities). Further, whilst consumption can be seen as an expression of individual and social identity, practice theories (e.g. Shove, 2010) raise significant questions in relation to this logic. Far from being agentic conscious decision makers, practice theories understand human actions and choices as a series of practices bound up by habits and socially organized routines (Luzecka, 2016).

Undoubtedly however, in a contemporary world dominated by reality TV, social media, and an ever-increasing fixation on individualized and capitalist aspirations (e.g. a big house, branded clothing), it is not surprising that individuals are often motivated to consume by their desire for a celebrity lifestyle. Indeed it is suggested that young people in particular are consumed with aspirations of fame and fortune, which they see as easily attainable by becoming celebrities (Gountas, Gountas, Reeves, \& Moran, 2012). The construction of the ease of these lifestyles is arguably an outcome of the ways in which, through contact on social media and reality TV for example, celebrities are now viewed as 'immediate strangers' (Schickel, 2000) in which people feel they know celebrities, which ones are 'nice', which ones are 'cool', 'funny', and which ones are like them/they want to be like. In this way, celebrities are no longer seen as distant unique individuals with unattainable and secretive lives. Of course, marketers have not missed this shift in thinking.

\section{How celebrity endorsement works - theoretical background}

For many years marketers have attempted to lure the potential consumer to their product as opposed to a competitor's. One enduring way of doing this is to utilise the aspirational other 
(e.g. celebrity) in marketing campaigns. McCracken's (1989) 'model of transference' is designed to explain how and why such a marketing strategy might be successful. McCracken argued that in order to persuade the potential consumer, 'transference' is a key mechanism through which celebrity endorsements increase intention to purchase. The model itself is fairly simple and is comprised of three stages. The first stage takes the position that in terms of public perception towards celebrities, certain celebrities are perceived as particular types of people. For example, an image of a known politician would arouse a particular 'imagination' in the public perception as to what the individual is like. The key for the marketer then is to establish which celebrity/celebrities possess the perceived characteristics aligned with how they would like their product to be perceived.

Stage two involves the explicit links between the celebrity and the product, in this sense the theory proposes that a process of 'transference' occurs in which the characteristics of the celebrity are 'transferred' to the perception of the product. Finally, in stage three, the potential consumer associates particular characteristics with particular products through the marketing campaigns/public endorsement and attempts to construct their identity, or express their self, through such product associations, resulting in the consumers' internalization of the new product image. Byrne, Whitehead, and Breen (2003), as a typical example, use McCracken's model to study Jamie Oliver's endorsement of/association with Sainsbury's supermarkets. Via his show, The Naked Chef, Oliver has become associated with informal and quick cooking with fresh ingredients. Through his endorsement, Sainsbury's and its products are imbued with Oliver's characteristics of 'cool' and 'quality', traits that consumers in turn come to associate with Sainsbury's.

Studies that examine the characteristics of successful celebrity endorsement tend to focus on either the endorser alone or the relationship between endorser and product or consumer. Celebrity characteristics are particularly important for the second phase of McCracken's model, transferring celebrity image to the endorsed product. Kelman (1961) makes the case for three key celebrity attributes: credibility, attractiveness and power. A credible endorser is seen to have information, abilities, or experiences germane to the product and is viewed as unbiased. An attractive spokesperson is likeable and familiar and bears some similarity to the consumer. Power, the capacity to reward and punish, can be evoked by celebrities whose public image is associated with power and authority (e.g., Clint Eastwood, Robert De Niro). The elaboration likelihood model of persuasion (Petty, Cacioppo, \& Schumann, 1983) indicates, however, that the positive and negative attributes (cues) associated with endorsers are more likely to shape attitudes among people with low involvement in the issue under consideration, rather than highinvolvement consumers, who are more prone to give diligent consideration to advocacy.

In McCracken's (1989) model, one of the elements that enables celebrity endorsement to be a success is to attempt to appeal to the types of selves individuals want to construct/express through their consumption behavior. Central to this element is the concept of 'congruence', which can be understood as the matching of identities across the three elements of the endorsement system: endorser, product and consumer. At one level, research exploring congruence in celebrity endorsement and marketing has examined the extent to which the endorser and the product match each other, with the closer matches leading to better intentionto-purchase outcomes (Kahle \& Homer, 1985; Kamins, 1990). This 'match-up hypothesis' (Fleck, Korchia, \& Le Roy, 2012) would suggest, for example, that a famous footballer would make a better spokesperson for Nike than would an equally famous musician. Furthermore, 
Fleck et al. (2012) compared product congruence to celebrity attractiveness and found congruence to be the more important predictor.

Research has turned however to the proposition that consumption can be a useful mechanism through which individuals feel they can construct/express their self (e.g. Dittmar, 2008). Research in this field makes the argument that the more that the consumer views the celebrity as like them/part of their referent group (self-congruity) or like their ideal self (ideal congruity), the more successful the advert is likely to be (Choi \& Rifon, 2012). Celebrities represent a high standard of achievement to which to aspire (i.e. the aspirational other). Indeed, given that Gountas et al. (2012) find that 'the desire for fame' is an ever-increasing aspiration among young people in many parts of the world, these aspirational others are central to the lives of the next generation of consumer. Finally, in terms of the difference between celebrity, product, and self-congruence, Choi and Rifon (2012) argue that celebrity/product congruence has a positive effect on attitude towards an advert, but not toward the brand or intention to purchase. Celebrity/audience congruence has a positive effect on opinion of advert and intention to purchase. Relative to self-congruity, ideal congruity is particularly powerful in matters of conspicuous consumption. Hence, it might be expected that, all else being equal, endorsers who most strongly represent an individual's ideal self will be the most successful in terms of motivating that individual to undertake the endorsed action.

Through their meta-analysis exploring the relationship between celebrity endorser effects and advertising effectiveness, Amos, Holmes and Strutton (2008) found that there were nine key predictors in research examining the link between celebrity endorsement and advertising effectiveness: (1) celebrity performance (e.g. success in their field); (2) negative information (e.g. scandal surrounding celebrity); (3) celebrity credibility; (4) celebrity expertise (e.g. legitimate voice on subject); (5) celebrity trustworthiness; (6) celebrity attractiveness; (7) celebrity familiarity; (8) celebrity likeability; and (9) celebrity/product fit. From these nine factors they found negative information about the celebrity exercised the largest impact on celebrity endorsement effectiveness in advertising, and credibility was the second largest predictor; however expertise, trustworthiness, and attractiveness all interact with credibility and thus these might not be separate factors.

Organizations can also serve as 'celebrity' endorsers as well as individuals do. Daneshvary and Schwer (2000) found that an endorsement by the Professional Rodeo Cowboys' Association increased intention to purchase various rodeo-related products. The authors theorized that the (endorser/product) match-up hypothesis should apply equally well to associations as to individuals. Inoue and Kent (2012) examined the potential for professional sports teams to encourage pro-environmental behavior. They framed their work around internalization, the process of aligning personal values with another group or person's values. Because sports teams can create a high level of identification, fans might be particularly driven to internalize any values their team exhibits and corporate social responsibility measures signal values that fans can then adopt. They find that positive environmental practices by a team do lead to more pro-environmental intentions on the part of individuals exposed to information about the team. This result is independent of whether or not the person is a fan, possibly via norm activation.

Aside from changing the perceptions of a product, celebrity endorsement can be effective in affecting behavior via norm activation. To be reliable norm activators, celebrities need to be successful (i.e. known for their accomplishments rather than their failures/scandals) but do not 
necessarily need to be people that the recipient consumer specifically identifies with or aspires to be like (Lindenberg, Joly, \& Stapel, 2011). Celebrities help remind people of their alreadyheld norms (activate them), which can spill over to related goals/norms. For example, in Lindenberg et al. (2011), celebrities telling people to not litter spilled over to buying organic food.

Whilst the above sections have highlighted theory surrounding the role of consumerism in contemporary lives, and also explored theory and research on the use of celebrities in advertising and product/company endorsement, the following section will explore how this is related to products seen as 'green' or 'ethical'.

\section{The rise of ethical and green products and the usefulness of the 'eco-celebrity'}

Ethical consumption is a concept incorporating a number of aspects such as ethical product purchase, boycotts, investment in ethical funds and deposits in ethical banks (Cowe \& Williams, 2001; Harrison, Newholm, \& Shaw, 2005). When we talk of these different aspects in terms of 'being ethical' a number of key features appear consistently throughout the corpus of definitions. For consumption practices to be defined as ethical they need to incorporate at least one of the key principles surrounding environmental, social concerns/human rights, animal welfare concerns and economic sustainability (Tallontire, Rentsendorj, \& Blowfield, 2001). More broadly ethical consumption is defined as “.... any practice of consumption in which explicitly registering commitment towards distant or absent others is an important dimension of the meaning of activity to the actors involved" (Barnett, Cloke, Clarke, \& Malpass, 2005, p. 29). Cowe and Williams (2001, p. 4) extend the definition of ethical to incorporate "self-interested health concerns" and use the expansion of organic foods to highlight this as they are not only concerned with the environment through pesticides but also the detrimental effects these chemicals have on the individual's personal wellbeing. It is now argued that "...the explicit marketing, accessibility and popularity of 'ethical' products is unprecedented" (Adams \& Raisborough, 2010, p. 256).

In parallel to the emergence of ethical consumption there has also been a push for 'greener' forms of consuming and living, in the context of rising concern for the environment. This is linked to a range of factors such as: the publication of Silent Spring (Carson, 1962); the antifur movement in the UK (Peattie, 1992); the publication of 'Limits to Growth' (Meadows, Meadows, Randers, \& Behrens, 1972); Chernobyl in 1986 and the torching of the Kuwait oil fields in 1991; increasing awareness of general environmental decline; unprecedented level of public reaction to specific human tragedy; the end of the Cold War; the discovery and proof of a hole in Ozone layer; media interest; and the increasing influence of environmental agencies and pressure groups, namely 'Friends of the Earth' (Spretnak \& Capra, 1990). By the late 1980s environmental awareness had emerged as a key issue gaining widespread acknowledgement throughout the western world, arguably growing to popular or fashionable status (Yearley, 1991). By the end of the 1980s human impact on the environment was increasingly being linked to the detrimental effects of consumption (in the world's richest nations) and not only production (Cowe \& Williams, 2001).

More recently, the consumer behavior literature has claimed that 'green is the new black' (Winge, 2008). Alexander (2013) argues that 'eco-celebrities' have become the newest device 
used by the market to boost their 'ethical' image. According to Boykoff, Goodman, and Littler (2010, p. 5) 'eco-celebrities' are contributing to the development of ethical products becoming the 'latest fashion trend', constructing them as desirable and socially accepted, through their ability to, "create and permeate what becomes permissible and normal, as well as desired in everyday discourses and practices". Through celebrities wearing and getting involved in 'green' fashion, it has been argued that a new discourse has emerged. With celebrities such as George Clooney, Lindsey Lohan and Julia Roberts lending their powerful influential status to promoting sustainable fashion on red carpets and in magazines, a new demand for stylish garments made with sustainable materials has developed (Winge, 2008). Indeed, Friedman (2013, p. np) argues "we must build a sustainably-focused consumer revolution and to do that we need a hero, who is cool and hip", further emphasizing the groundswell there is concerning the potential of the 'eco-celebrity' in creating a new vision for contemporary consumerism.

Boykoff and Goodman (2009, p. 396) note that celebrities are "important non-nation-state figures in the discursive, material, and media politics" related to environmental issues and have the popular authority to give priority to some environmental issues over others. Celebrities have been involved in a range of environmental issues, most notably conservation (e.g. Sting, David Attenborough, and Jack Johnson) and climate change (e.g. Leonardo DiCaprio, Robert Redford).

Celebrities play more of a mobilization role than one of changing public opinion. Jacques Cousteau has been held up as the most effective celebrity involved in conservation. His advocacy helped funnel public opinion against the 1988 Antarctic Minerals Treaty, which would have opened the continent to mining. Cousteau instead helped to make Antarctica into a World Park (Shortis, 2015). Anderson (2011) notes that the ability to create headlines endows them with particular currency in the domain of climate change. She also finds that celebrities tend to follow rather than create news coverage, though they can help extend the coverage beyond what otherwise would have occurred (Anderson, 2011), though exceptions of course exist. Leonardo DiCaprio's raising the issue of climate change during his best-actor acceptance speech at the 2015 Academy Awards corresponded to a record-setting spike in tweets and Google searches related to "climate change" and "global warming" (Leas et al., 2016).

Boykoff et al. (2010, p. 2) call celebrities "a new species of charismatic megafauna," reducing the distance in time and space associated with climate change and making it more locally salient. Whist there is scant evidence that celebrity-driven education and awareness-raising translates into changed behavior, Jacobsen (2011) found an increase in purchases of carbon offsets within a geographic area immediately after screenings of An Inconvenient Truth, but no evidence of persistence (repeat purchasing a year later). Regarding pro-environmental consumption patterns, the 'green commodity' discourse indicates that environment-associated products can become a valued avenue for consumption when consumers learn to seek status from eco-friendly goods (van der Wal, van Horen, \& Grinstein, 2016). This potential effect is particularly strong in the case of 'conspicuous conservation,' wherein the adoption/use of green goods and services is visible to others and therefore more status-enhancing (Griskevicius, Tybur, \& Van den Bergh, 2009). Celebrities can act both to raise the profile of a given product (making it more salient/visible) and to associate that product with the quality of 'greenness.' Creating 'green chic appeal' is not a straightforward process. Green marketing is most effective when it appears bottom-up and that the endorsement of celebrities is unsolicited (Ottman, Stafford, \& Hartman, 2006). 
Finally, the best-documented instance of celebrities influencing popular opinion with regards to transportation mode is in the domain of hybrid vehicles, particularly the Toyota Prius (Ottman et al., 2006). Several famous actors arrived at the 2003 Academy Awards in Toyota Prii in a coordinated effort to show support for reducing American dependence on foreign oil (Heffner, Kurani, \& Turrentine, 2005). When interviewed about their hybrid vehicles, owners frequently acknowledge that there are symbolic benefits in the green reputation of hybrids and that this reputation is reinforced by celebrity owners (Heffner et al., 2005).

\section{Role model advocacy in transportation: framework and illustrative analysis}

Our review of the literature on role model advocacy and celebrity endorsement, focused in the context of ethical and green consumption, has allowed us to conceptually extend towards an understanding of how role model endorsement may function in the case of transport. Based on the literature and our own expertise in transport and consumption behavior, we have identified key dimensions of role model endorsement in transport (Table 1). These dimensions are presented in binary form, with each binary aligning with a particular criterion (e.g. Criterion'trip purpose, Binary - 'Necessity/Luxury'). The dimensions are presented in binary form for heuristic purposes: we recognize that that the dimensions may blur into each other; for instance, a role model may be simultaneously a celebrity and a politician, and the border between a trip purpose that is necessity versus luxury is not always perceived as so black and white. Nonetheless, these dimensions allow for an illustrative analysis of the forms in which role model advocacy in transport may take place, including identification of the dimensional configurations most likely to form the basis for rendering significant interventions for sustainable transport behavior.

Table 1: Key dimensions of role model endorsement in transport

\begin{tabular}{|l|l|l|}
\hline Criterion & \multicolumn{2}{|c|}{ Dimensions } \\
\hline Role model type & Politician & Celebrity \\
\hline Formality & Unsolicited association & Solicited advertising \\
\hline Nature of performance & Authentic & Inauthentic \\
\hline Unit & Individual & Organization \\
\hline Trip purpose & Necessity & Luxury \\
\hline Visibility & Private & Public \\
\hline Self-comparison & Aspirational & Dissociative \\
\hline Environmental outcome & Desirable & Undesirable \\
\hline
\end{tabular}

Taking the cases of George Clooney, Daniel Craig and Angela Merkel, what follows will briefly attempt to illustrate how the key dimensions of role model endorsement in transport materialize in practice.

George Clooney is a famous celebrity (role model type, individual unit) who is a multiple Golden Globe and Academy award winning actor featuring in blockbuster films such as Batman and Robin, The Perfect Storm, Ocean's Eleven, Ocean's Twelve, and Ocean's Thirteen, along with the award winning television show ER. Alongside his acting career 
Clooney has pursued a number of humanitarian and politically driven paths and has featured in the American magazine Time top 100 most influential people in the world (Time Magazine, 2016). In 2005 Clooney took delivery of the first Tango Electric Car and posed for a photo with the new purchase (unsolicited association). The nature of this performance can be seen as inauthentic given his links to activism and the scripted feel of the image. As this product is produced as a commuter vehicle to reduce pollution and congestion in cities the trip purpose can be understood as necessity. The image was produced for a visibly public audience through the explicit, though non-solicited endorsement with Clooney positioned as an aspirational figure through which the purchasing of the Tango vehicle enables members of the public to attempt to embody some of the characteristics of Clooney. Ultimately the above dimensions facilitate the promotion of environmentally desirable transport practices.

In a similar light to George Clooney, Daniel Craig is a well-respected and award winning actor (Role model type: celebrity; individual unit) most recently famous for playing the symbolic character James Bond. In 2013 Craig featured as the face of the new Range Rover Sport in its advertising campaign (solicited advertising). As the advertising was entirely scripted it can be understood as inauthentic in that it was not part of Craig's everyday transport mobility. Whilst there is not an explicit trip purpose within the advert, it can be suggested that with a starting price in the region of $£ 50,000$ this features in the 'luxury' category. As with all advertising the visibility was indeed public with Craig and his film character of James Bond very much an aspirational figure. Finally, the combination of the above components attempts to result in an increase in an environmentally undesirable transport mode.

Finally, German Chancellor, Angela Merkel (Role model type: politician; individual unit) has for a number of years been photographed next to a range of electric cars and a number of trade and commerce events (Wort, 2014). Such activity is largely unsolicited in that it is unlikely and certainly unreported that Merkel has received money for the endorsement, though her party has been accused of accepting electoral funding by car maker BMW (Handelsblatt, 2013). However, there is some level of soliciting in these events given Merkel's position as German Chancellor and her government's official policy on renewable energy. Thus the nature of performance might be understood as inauthentic with the visibility being public and the trip type again difficult to assess as electric cars are perceived as being less luxury then their fossil fuel burning counterparts. As Merkel is the chancellor of Germany she will be an aspirational figure to some, however she does not fit the image of a celebrity and thus given Gountas et al.'s (2012) assertion that young people are aspiring to live 'celebrity lifestyles' we could perhaps suggest Merkel will likely be seen as dissociative. Finally, the environmental outcome of this endorsement is the promotion of more environmentally desirable forms of transport.

\section{Discussion}

Throughout the above we have made both the theoretical and illustrative case for the potential that role model advocacy offers the future of sustainable consumption, and more specifically sustainable transport futures. It is clear to see that the evidence from marketing and consumer psychology overwhelmingly suggests that celebrity endorsement increases product purchase intention and ultimately sales. Furthermore, in our review we demonstrate the ways in which theorists have suggested, and in some cases, empirically tested, the usefulness of celebrity endorsement for 'green' and 'ethical' products. We then speculated on the ways in which this 
movement can be utilized to tackle one of the key issues in contemporary society, that is, the excessive use of unsustainable transport practices that have negative implications for both the environment and people. However, what follows in this section shall argue that whilst this might offer some potential for a sustainable transport future, there needs to be considerable caution when taking this path as there are some substantive, and potentially incurable critiques of this approach.

When considering all of the material presented in this article it seems clear that utilizing celebrities/role models is indeed one way in to achieve a more sustainable transport future. However, at the heart of this issue is the rapid growth in national and international transport, in what has been defined as 'hypermobility' (Cohen \& Gössling, 2015). Therefore it can be suggested that in much the same way as with the 'ethical consumption' movement, we are yet again in danger of falling foul of Johnston's (2002) critique concerned with turning to consumption in order to tackle the inherent problems with consumption. Social marketing is similarly critiqued for being trapped within, and not questioning, a broader neo-liberal growth paradigm (Hall, 2013). To draw again on some of the issues leveled against 'ethical consumption', we can be reminded of Goodman and Goodman's (2001) assertion that such an approach fails to adequately address the inherent dynamics within current consumption issues, instead, simply providing a 'green gloss' to the inequalities of production and consumption in the current capitalist system. Here then, when we return our thoughts to the material presented earlier in this article exploring the link between the self and consumption, and the increasing desire amongst young people to be like celebrities, it would be suggested that the use of celebrity endorsement in sustainable transport does little more than further enhance a system already enshrined with consumer capitalist ideologies that are simply concerned with product sales and a consumptive form of living (e.g. Weiskel, 2005). Alexander (2013) takes this issue further to suggest that celebrity engagement with such ethical endorsement/association activities is not a form of 'ethical crusade', but rather a necessity for status and social capital in contemporary celebrity lives. Indeed, it would not be beyond the realms of the imagination to see clear links between celebrity endorsement for sustainable transport, and Blackmore's (2009, p. 176) assertion that "“[1]iving lightly on the planet' and 'reducing your environmental impact' becomes, paradoxically, a consumer-product growth industry".

Building on this element of the paradox between consumerism, celebrities and environmentalism, Fletcher (2015) argues that the 'charismatic authority' given to celebrities can serve to hide the contradictions of neoliberal environmental policy in which the individual consumer is left to shoulder the issues that social/government policy are failing to address. This connection between celebrities and the neoliberalization of environmental issues has been made by numerous authors. For example, these contradictions come into even sharper focus through the actions of celebrity green entrepreneurs like Richard Branson (Prudham, 2009). Partzsch (2016) observes that, in the past two decades, power has shifted from state actors towards philanthropists, celebrities, and social entrepreneurs, creating problems for democratic accountability and legitimacy. Anderson (2011) offers a more ambivalent account of the situation through her critical review of media coverage of climate/environmental issues and the potential role of celebrities in moving the broader public to action. She notes that there is a "tendency for the celebritization of climate change to promote individualist rather than collective frames for action" (ibid, p. 535), but finds that whilst this is the case, the real importance is on the ways in which the issues are framed. Further, whilst Boykoff and 
Goodman (2009) warn of celebrities promoting 'individualistic frames', they also express some uncertainty through their acknowledgement of the value of celebrities in creating 'extended networks' that promote value and meaning, offering possible voices of 'authority' on issues such as climate change and potentially mobilizing public action.

Therefore, it appears that within this approach we are faced with many of the existing critiques of a broader neoliberal agenda in which consumers are embedded within the broader ideology of individualism (Ray, 2005) or what Beck (1992) refers to as the 'individualization thesis'. Within this 'individualization thesis' the individual is no longer constructed through their social position (e.g. religion, nationality, employment role) but rather the individual is free, autonomous and able to reflect on and construct their own identity and behaviors (Giddens, 1991). Thus it is this premise that resides at the centre of attempts to utilize celebrity endorsement to change consumption behaviour: the links between the aspirational celebrity identity, and the social and political connotations with 'sustainable' forms of consumption, results in the illusion of the consumer being able to make change happen, and take part in a political act, through one's consumption practices (Spaargaren, 2010).

Of course, what this neoliberal individualized focus fails to recognize is the social context in which individuals are acting that enables but also constrains certain individuals to act in certain ways (Akenji, 2014; Stets, 2003; Swait et al., 2002). For example, Adams and Raisborough (2008) examine social class in relation to the purchasing of FairTrade products and suggest that rather than an individual's morals being the barrier or facilitator of consuming FairTrade, classbased 'othering' is a central feature to such consumption practices. Such 'othering' functions through the middle class 'good' that have the financial power to consume FairTrade, and the working class 'bad' that do not have the financial capital and thus are judged as 'less moral'. Therefore, far from offering an 'ethical' alternative to consumption, Adams and Raisborough suggest that such practices have the potential to encourage/create outgroup antagonism and elitism.

Indeed, placing the responsibility of tackling environmental issues on the 'agentic' consumer not only creates significant 'othering' in societies, but also goes some way in exonerating governments and industry from any responsibility in the process, a critique captured in approaches advocating practice theories (e.g. Luzecka, 2016; Shove, 2014). As Rogers (2010, p. 7) quite aptly comments, "I've come to realise that my toxic emissions are not solely my own. Instead they are linked to the larger socio-economic system that actually depends on pollution to maintain its wellbeing". Barr, Gilg, and Shaw (2011a) advance a similar critique of governance that devolves ecological responsibility to the public as 'citizen-consumers'; the authors argue that encouraging the public to engage in pro-environmental behavior through consumption choices is a viewpoint trapped within the confines of neoliberalism, which obscures the need for change at structural levels.

Therefore, in response to our initial question of "how behavior can be influenced at large scales, and over comparably short periods of time, and whether significant others such as celebrities can inspire more sustainable transport behavior on larger societal scales", we suggest here that celebrity endorsement and role model advocacy do have the potential to scale up behavior change initiatives in relation to sustainable transport. However we do urge some caution in relation to the broader understanding of the individual in relation to consumption, aspirations to celebrity lifestyles, sustainability and neoliberalism, as has been shown through the 
numerous critiques highlighted in this section. We see scope in the use of practice theories, as highlighted above, which suggest that individual agency needs to be reconsidered in light of the mindless, unconscious, socially organised habits, routines and shared practical understandings that comprise the social world (Luzecka, 2016; Schatzki, Cetina, \& von Savigny, 2001). Practice theories can move the focus of role model advocacy and celebrity endorsement beyond a focus on individuals, by giving attention to the shared practical understandings that might also induce cultural change in organizational settings and social norms more widely. Therefore, on the balance of this review we arrive at a position of ambivalence to the potential promise and pitfalls of celebrity endorsement and role model advocacy, similar to that expressed by Boykoff and Goodman (2009).

\section{Conclusion}

This article has offered a critical review of the literature on role model advocacy and celebrity activism, and how these concepts have been mobilized to address environmental issues. Its aim has been to conceptually assess the potential for extending these perspectives to the context of forming effective interventions for encouraging sustainable transport behavior. Our review has shown that substantial effort has been invested in social marketing interventions that use aspirational role models, such as celebrities, to influence public opinion on social issues, but with little extension to the problem of sustainable transport. When extended to the context of environment-associated products, stimulating pro-environmental behavior has been shown to be more effective when consumers perceive status-enhancement from the conspicuous consumption of eco-friendly goods (e.g. Griskevicius et al., 2009). This 'green chic appeal' will most effective through bottom-up marketing wherein any use of celebrity endorsement is unsolicited (Ottman et al., 2006).

We have created a bridge between such insights from celebrity endorsement and 'ethical' and 'green' consumption to assess how celebrities and politicians might exercise referent power to influence social norms surrounding sustainable transport. This has been accomplished through the identification of eight key dimensions of role model endorsement in transport, with these applied to a series of examples that illustrate how celebrity and political role models have influenced transport cultures. It emerged that unsolicited associations, rather than solicited advertising will be more powerful, regardless of whether these are perceived as in/authentic. These must be publicly visible appeals, which can apply to a range of trip purposes (luxury or necessity), suggesting that leisure, commuting, business and domestic travel behavior may all be susceptible to role model endorsement influence, as long as the role model is aspirational in terms of self-comparison, with celebrities likely to be more influential than politicians in engendering sustainable transport behavior.

While these eight dimensions provide a starting point for configuring interventions based on role model endorsement for sustainable transport, like all social marketing, any such efforts aimed at engendering desirable transport futures will face at least two major challenges. The first will be the powerful solicited advertising of commercial marketing activities encouraging undesirable transport futures, as our discussion of Daniel Craig as the face of Range Rover Sport exemplified. Wymer (2010) has warned that social marketing campaigns are likely to be rendered ineffective when pitted against such efforts. The second challenge, as shown by the desirable behavior associated with famous actors arriving at the Academy Awards in hybrid 
electric cars (Heffner et al., 2005), is that sustainable transport consumption, is still consumption, with celebrities who advocate a desirable transport future through the marketplace doing little more than hiding the contradictions of neoliberal environmental policy (Fletcher, 2015).

Our examples relied on individuals, rather than organizations, as the unit of analysis. Despite the challenges above associated with role model endorsement for sustainable transport, there exists a need for empirical research on the potential for organizations, such as sporting clubs, to engender behavioral change amongst supporters travelling to events. Furthermore, this article can serve as basis for wider empirical work aimed at measuring the potential for role model endorsement to stimulate behavioral change in transport consumption. Experimental methods will likely be useful in such efforts, and these can draw upon the key dimensions of role model transport we have identified in Table 1. Future studies employing practice theories will additionally be useful in examining how role model advocacy can be used to disrupt the shared practical understandings that presently constitute social norms, with a view towards underpinning interventions for cultural change in organizational settings. Despite the continued challenges of commercial marketing by the transport industries that pushes us towards environmentally destructive transport behavior, and the limitations of achieving meaningful social change within the confines of market logics, it remains necessary to press for desirable transport futures not just at governance and industry levels, but also within the daily trenches of consumption itself.

\section{Acknowledgements}

The authors would like to thank attendees of the 2016 Freiburg workshop on Desirable Transport Futures for their feedback on this work.

\section{References}

Adams, M., \& Raisborough, J. (2008). What can sociology say about FairTrade? Situating reflexivity in ethical consumption. Sociology., 42(6), 1165-1182.

Adams, M., \& Raisborough, J. (2010). Making a difference: ethical consumption and the everyday. The British Journal of Sociology 61, 256-274.

Akenji, L. (2014). Consumer Scapegoatism and Limits to Green Consumerism. Journal of Cleaner Production, 63, 13-23.

Alexander, J. (2013). The Case of The Green Vampire: Eco-Celebrity, Twitter and Youth Engagement. Celebrity Studies, 4(3), 353-368.

Amos, C., Holmes, G., \& Strutton, D. (2008). Exploring the relationship between celebrity endorser effects and advertising effectiveness: A quantitative synthesis of effect size. International Journal of Advertising, 27(2), 209-234.

Ampt, E., \& Gleave, S. D. (2004). Understanding voluntary travel behaviour change. Transport Engineering in Australia, 9, 53-66.

Anderson, A. (2011). Sources, media, and modes of climate change communication: the role of celebrities. Wiley Interdisciplinary Reviews: Climate Change, 2(4), 535-546.

Andreasen, A. R. (1994). Social marketing: its definition and domain. Journal of Public Policy \& Marketing, 108-114. 
Banister, D. (2005). Unsustainable transport: city transport in the new Century. London: Routledge.

Barnett, C., Cloke, P., Clarke, N., \& Malpass, A. (2005). Consuming Ethics: Articulating the subjects and spaces of ethical consumption. Antipode, 23-45.

Barr, S., Gilg, A., \& Shaw, G. (2011a). Citizens, consumers and sustainability:(Re) Framing environmental practice in an age of climate change. Global Environmental Change, 21(4), 1224-1233.

Barr, S., Gilg, A., \& Shaw, G. (2011b). 'Helping People Make Better Choices': Exploring the behaviour change agenda for environmental sustainability. Applied Geography, 31(2), $712-720$.

Bauman, Z. (2001). Consuming Life. Journal of Consumer Culture, 1(1), 9-29.

Baumeister, R. F. (1987). How the self became a problem: A psychological review of historical research Journal of personality and social psychology, 52, 163-176.

Beck, U. (1992). Risk Society: towards a new modernity. London: Sage.

Belk, R. W. (1988). Possessions and the extended self. Journal of consumer research, 15(2), $139-168$.

Blackmore, C. (2009). Individual and Collective Responsibility. In M. Reynolds, C. Blackmore, \& M. Smith (Eds.), Environmental Responsibility Reader (pp. 163-241). London: Zed Books.

Bourdieu, P. (1984). Distinction: A social critique of the judgement of taste. London: Routledge.

Boykoff, M., \& Goodman, M. (2009). Conspicuous redemption? Reflections on the promises and perils of the 'celebritization' of climate change. Geoforum, 40(3), 395-406.

Boykoff, M., Goodman, M., \& Littler, J. (2010). 'Charismatic megafauna': The growing power of celebrities and pop culture in climate change campaigns. Environment, Politics and Development Working Paper Series, WP, 28.

Byrne, A., Whitehead, M., \& Breen, S. (2003). The naked truth of celebrity endorsement. British Food Journal, 105(4/5), 288-296.

Carson, R. (1962). Silent Spring. London: Houghton Mifflin.

Choi, S. M., \& Rifon, N. J. (2012). It is a match: The impact of congruence between celebrity image and consumer ideal self on endorsement effectiveness. Psychology \& Marketing, 29(9), 639-650.

Cohen, S. A., \& Gössling, S. (2015). A darker side of hypermobility. Environment and Planning A, 47(8), 166-1679.

Cohen, S. A., Higham, J., Gössling, S., Peeters, P., \& Eijgelaar, E. (2016). Finding effective pathways to sustainable mobility: bridging the science-policy gap. Journal of Sustainable Tourism, 24(3), 317-334.

Cowe, R., \& Williams, S. (2001). Who are the ethical consumers? : Co-operative Bank report.

Cushman, P. (1995). Constructing the self, Constructing America. Reading, MA: AddisonWesley.

Daneshvary, R., \& Schwer, R. K. (2000). The association endorsement and consumers' intention to purchase. Journal of consumer marketing, 17(3), 203-213.

Dittmar, H. (2008). Consumer Culture, Identity and Well-Being: The Search for the 'Good Life' and the 'Body Perfect'. Hove: Psychology Press.

EEA. (2015). Trends and projections in Europe 2015 - Tracking progress towards Europe's climate and energy targets. Retrieved from http://www.eea.europa.eu/publications/trends-and-projections-in-europe-2015.

Featherstone, M. (1991). Postmodernism and consumer culture. London: Sage. 
Fleck, N., Korchia, M., \& Le Roy, I. (2012). Celebrities in advertising: looking for congruence or likability? Psychology \& Marketing, 29(9), 651-662.

Fletcher, R. (2015). Blinded by the stars? Celebrity, fantasy, and desire in neoliberal environmental governance. Celebrity Studies, 6(4), 457-470.

Friedman, J. (2013). Making Sustainability 'Cool'. Retrieved from http://www.huffingtonpost.com/john-friedman/making-sustainabilitycoo_b_3525939.html.

Giddens, A. (1991). Modernity and Self-Identity: self and society in the late modern age. Stanford: Stanford University Press.

Gilbert, R., \& Perl, A. (2008). Transport revolutions: moving people and freight without oil. London: Earthscan.

Goodman, D., \& Goodman, M. (2001). Sustaining Foods: Organic Consumption and the Socio-Ecological Imaginary. In M. J. Cohen \& J. Murphy (Eds.), Exploring Sustainable Consumption: Environmental Policy and the Social Sciences. Oxford: Elsevier Science.

Goodman, M., \& Littler, J. (2013). Celebrity ecologies: Introduction. Celebrity Studies, 4(3), 269-275.

Gössling, S., \& Cohen, S. (2014). Why sustainable transport policies will fail: European Union climate policy in the light of transport taboos. Journal of Transport Geography, 39, 197-207.

Gountas, J., Gountas, S., Reeves, R. A., \& Moran, L. (2012). Desire for fame: scale development and association with personal goals and aspirations. Psychology \& Marketing, 29(9), 680-689.

Griskevicius, V., Tybur, J. M., \& Van den Bergh, B. (2009). Conspicuous Conservation: Promoting Green Consumption Through Status Competition. In A. McGill \& S. Shavitt (Eds.), Advances in Consumer Research Volume 36 (pp. 206-209). Duluth, $\mathrm{MN}$ : Association for Consumer Research.

Hall, C. M. (2013). Framing behavioural approaches to understanding and governing sustainable tourism consumption: beyond neoliberalism, "nudging" and "green growth"? . Journal of Sustainable Tourism, 21(7), 1091-1109.

Hall, C. M. (2014). Tourism and Social Marketing. London: Routledge.

Handelsblatt. (2013). BMW hat Merkel im Sack [BMW owns Merkel]. Retrieved from http://www.handelsblatt.com/politik/deutschland/riesen-spende-an-die-cdu-bmw-hatmerkel-im-sack/8934938.html

Harrison, R., Newholm, T., \& Shaw, D. (2005). Defining the ethical consumer. In R. Harrison, T. Newholm, \& D. Shaw (Eds.), The Ethical Consumer (pp. 1-8). London: Sage.

Heffner, R. R., Kurani, K., \& Turrentine, T. (2005). Effects of vehicle image in gasolinehybrid electric vehicles. Paper presented at the 21 st Worldwide battery, Hybrid and Fuel Cell Electric Vehicle Symposium and Exhibition Monaco.

Higham, J., Cohen, S. A., Cavaliere, C. T., Reis, A., \& Finkler, W. (2016). Climate change, tourist air travel and radical emissions reduction. Journal of Cleaner Production, 111, 336-347.

Higham, J., Cohen, S. A., Peeters, P., \& Gössling, S. (2013). Psychological and behavioural approaches to understanding and governing sustainable mobility. Journal of Sustainable Tourism, 21(7), 949-967.

Hook, W., \& Replogle, M. (1996). Motorization and non-motorized transport in Asia: Transport system evolution in China, Japan and Indonesia. Land Use Policy, 13(1), 69-84. 
Inoue, Y., \& Kent, A. (2012). Investigating the role of corporate credibility in corporate social marketing: A case study of environmental initiatives by professional sport organizations. Sport Management Review, 15(3), 330-344.

Jacobsen, G. (2011). The Al Gore effect: An inconvenient truth and voluntary carbon offsets. Journal of Environmental Economics and Management, 61, 67-78.

Johnston, J. (2002). Consuming social justice: fair trade shopping and alternative development In J. Goodman (Ed.), Protest and Globalisation (pp. 39-56). Annandale: Pluto Press.

Kahle, L. R., \& Homer, P. M. (1985). Physical attractiveness of the celebrity endorser: A social adaptation perspective. Journal of consumer research, 11(4), 954-961.

Kamins, M. A. (1990). An investigation into the "match-up" hypothesis in celebrity advertising: When beauty may be only skin deep. Journal of advertising, 19(1), 4-13.

Kelman, H. C. (1961). Processes of opinion change. Public opinion quarterly, 25(1), 57-78.

Kenworthy, J. R., \& Laube, F. B. (1999). Patterns of automobile dependence in cities: an international overview of key physical and economic dimensions with some implications for urban policy. Transportation Research Part A: Policy and Practice, 33(7), 691-723.

Kornberger, M., \& Brown, A. D. (2007). Ethics' as a discursive resource for identity work. Human Relations, 60(3), 497-518.

Lawler, S. (2005). Disgusted Subjects: the making of middle-class identities. The Sociological Review, 3, 429-446.

Leas, E. C., Althouse, B. M., Dredze, M., Obradovich, N., Fowler, J. H., Noar, S. M., . . . Ayers, J. W. (2016). Big data sensors of organic advocacy: The case of Leonardo DiCaprio and climate change. PloS one, 11(8), e0159885.

Leighton, D. (2003). Happy Days? Freedom and security in a consumer society. Renewal: A Journal of Labour Politics, 11, 202-209.

Lindenberg, S., Joly, J. F., \& Stapel, D. A. (2011). The Norm-Activating Power of Celebrity The Dynamics of Success and Influence. Social Psychology Quarterly, 74(1), 98-120.

Luzecka, P. (2016). “Take a gap year!” A social practice perspective on air travel and potential transitions towards sustainable tourism mobility. Journal of Sustainable Tourism, 24(3), 446-462.

Mackay, H. (1997). Introduction: consumption and everyday life. In H. Mackay (Ed.), Consumption and everyday life. London: Sage.

Mackintosh, M., \& Mooney, G. (2000). Identity, inequality and social class. In K. Woodward (Ed.), Questioning identity: gender, class, nation. London: Routledge.

McCracken, G. (1989). Who is the celebrity endorser? Cultural foundations of the endorsement process. Journal of consumer research, 16(3), 310-321.

McCurdy, P. (2013). Conceptualising celebrity activists: the case of Tamsin Omond. Celebrity Studies, 4(3), 311-324.

Meadows, D. H., Meadows, D. L., Randers, J., \& Behrens, W. W. (1972). Limits to Growth. Washington: Potomac Associates.

Miller, D. (1997). Consumption and its consequences. In H. Mackay (Ed.), Consumption and everyday life. London: Sage.

Nayak, A. (2006). Displaced Masculinities: Chavs, Youth and Class in the Post-Industrial City. Sociology, 40, 813-831.

Okokon, E. O., Turunen, A. W., Ung-Lanki, S., Vartiainen, A. K., Tiittanen, P., \& Lanki, T. (2015). Road-Traffic Noise: Annoyance, Risk Perception, and Noise Sensitivity in the Finnish Adult Population. International Journal of Environmental Research and Public Health, 12(6), 5712-5734. 
Ottman, J. A., Stafford, E. R., \& Hartman, C. L. (2006). Avoiding green marketing myopia: Ways to improve consumer appeal for environmentally preferable products. Environment: science and policy for sustainable development, 48(5), 22-36.

Partzsch, L. (2016). Powerful Individuals in a Globalized World. Global Policy, Early View. doi:10.1111/1758-5899.12367

Peattie, K. (1992). Green Marketing. London: Pitman Publishing.

Peattie, K., \& Peattie, S. (2009). Social marketing: A pathway to consumption reduction? Journal of Business Research, 62, 260-268.

Peeters, P., Higham, J., Kutzner, D., Cohen, S., \& Gössling, S. (2016). Are technology myths stalling aviation climate policy? . Transportation Research Part D, 44, 30-42.

Petty, R. E., Cacioppo, J. T., \& Schumann, D. (1983). Central and peripheral routes to advertising effectiveness: The moderating role of involvement. Journal of consumer research, 10(2), 135-146.

Prudham, S. (2009). Pimping climate change: Richard Branson, global warming, and the performance of green capitalism. Environment and Planning A, 41(7), 1594-1613.

Pucher, J., \& Buehler, R. (2012). City cycling. Cambridge: MIT Press.

Ray, C. (2005). Individualisation and the third age. Centre for Rural Economy discussion paper Series(3).

Richens, M. L. (1991). Social comparison and idealized images of advertising. Journal of consumer research, 18, 1-83.

Rogers, H. (2010). Green Gone Wrong: Dispatches from the Front Lines of Eco-Capitalism. London: Verso.

Schatzki, T. R., Cetina, K. K., \& von Savigny, E. (2001). The practice turn in contemporary theory. London: Routledge.

Schickel, R. (2000). Intimate strangers: The culture of celebrity in America. Chicago: Ivan R Dee.

Shortis, E. (2015). "Who can resist this guy? rdquo; Jacques Cousteau, Celebrity Diplomacy, and the Environmental Protection of the Antarctic. Australian Journal of Politics \& History, 61(3), 366-380.

Shove, E. (2010). Beyond the ABC: Climate Change Policy and Theories of Social Change. Environment and Planning A, 42(6), 1273-1285.

Shove, E. (2014). Putting practice into policy: Reconfiguring questions of consumption and climate change. Contemporary Social Science, 9(4), 415-429.

Skeggs, B. (2003). Class, Self and Culture. London: Routledge.

Solomon, M., Bamossy, G., Askegaard, S., \& Hogg, M. K. (2006). Consumer Behaviour: A European Perspective. Harlow: Pearson.

Spaargaren, G. (2010). Citizen-Consumers as Agents of Change in Globalising Modernity: The Case of Sustainable Consumption. Journal of Sustainability, 2, 1887-1908.

Spretnak, C., \& Capra, F. (1990). Green Politics: The global promise. London: Paladin.

Stanley, J. K., Hensher, D. A., \& Loader, C. (2011). Road transport and climate change: stepping off the greenhouse gas. Transportation Research Part A: Policy and Practice, 45, 1020-1030.

Stets, J. (2003). Bringing Identity Theory into Environmental Sociology. Sociological Theory, 21(4), 398-423.

Swait, J., Adamowicz, W., Hanemann, M., Diederich, A., Krosnick, J., Layton, D., . . Tourangeau, R. (2002). Context Dependence and Aggregation Disaggregate Choice Analysis. Marketing Letters, 13(3), 195-205.

Tallontire, A., Rentsendorj, E., \& Blowfield, M. (2001). Ethical Consumers and Ethical Trade: A Review of Current Literature. Policy Series 12. Chatham, Natural Recourses Limited. 
Therkelsen, A., \& Gram, M. (2008). The Meaning of Holiday Consumption: Construction of self among mature couples. Journal of Consumer Culture, 8, 269-292.

van der Wal, A. J., van Horen, F., \& Grinstein, A. (2016). The paradox of 'green to be seen': Green high-status shoppers excessively use (branded) shopping bags. International Journal of Research in Marketing, 33(1), 216-219.

Weiskel, T. (2005). From Sidekick to Sideshow - Celebrity, Entertainment, and the Politics of Distraction. American Behavioural Scientist, 49(3), 393-409.

Winge, T. M. (2008). "Green is the new black": Celebrity chic and the "green" commodity fetish. Fashion Theory, 12(4), 511-523.

Wort. (2014). Electric cars fail to rev up car-mad Germans. Retrieved from http://www.wort.lu/en/lifestyle/car-data-report-electric-cars-fail-to-rev-up-car-madgermans-53eaf7d5b9b39887080549cd

Wymer, W. (2010). Rethinking the boundaries of social marketing: Activism or advertising? Journal of Business Research, 63(2), 99-103.

Yearley, S. (1991). The Green Case: A Sociology of Environmental Issues, Arguments and Politics. London: HarperCollins. 